\title{
Current state of Arctic mercury cycling: Sources, pathways and levels (Ashu Dastoor and over 15 co- authors)

\author{
ASHU DASTOOR
}

Environment and Climate Change Canada

Presenting Author: ashu.dastoor@canada.ca

Findings of a recent review of abiotic $\mathrm{Hg}$ in the Arctic (Arctic Monitoring and Assessment Programme, 2021) will be summarized in this presentation. An up-to-date understanding of the emissions, transport and deposition pathways, source apportionment, inter-compartmental fluxes and mass budgets of total $\mathrm{Hg}$ in Arctic environments is developed based on observations and multi-model modeling. Total $\mathrm{Hg}$ levels in Arctic air $(\sim 300 \mathrm{Mg})$, permafrost soils $(\sim 600 \mathrm{Gg}, 0-3 \mathrm{~m})$, seasonal snowpacks $(\sim 40 \mathrm{Mg})$, glaciers $(\sim 2,400 \mathrm{Mg})$, sea ice $(\sim 10 \mathrm{Mg})$, and ocean waters $(\sim 1,900 \mathrm{Mg})$ are revised. $\mathrm{Hg}$ fluxes for terrestrial systems (anthropogenic, soils/vegetation and wildfire emissions and deposition) and the Arctic Ocean (deposition/evasion, river export, coastal erosion, ocean inflow/outflow, sea ice export, and sediment burial) are constrained. Terrestrial $\mathrm{Hg}$ fluxes north of $60^{\circ} \mathrm{N}$ suggest an approximate balance of $\mathrm{Hg}$ in soils, but the observed dominant $\mathrm{Hg}(0)$ deposition to terrestrial systems (vegetation/soils uptake) is underestimated in models, and wildfire emissions remain highly uncertain. A net $\mathrm{Hg}$ input of $>50 \mathrm{Mg} / \mathrm{y}$ to the Arctic Ocean waters is implied, which is explained using uncertainties in fluxes, and recent GEOTRACES cruises observations. $\mathrm{Hg}$ fluxes are found relatively better constrained for river export, and oceanic inflow/outflow. Direct link between terrestrial $\mathrm{Hg}$ deposition and river $\mathrm{Hg}$ export is not yet fully possible, but model ensemble deposition to pan-Arctic watersheds north of $60^{\circ} \mathrm{N}$ is consistent with annual river $\mathrm{Hg}$ exports, and suggests that majority of river $\mathrm{Hg}$ is derived from seasonal snowpacks and surface soils during spring freshet. Permafrost thaw is an important $\mathrm{Hg}$ source to downstream ecosystems, but current observations are insufficient to estimate the overall impact. The sediment-bound $\mathrm{Hg}$ in glacier-fed streams is notably higher than the $\mathrm{Hg}$ levels in glacial-ice meltwater, resulting from the mobilization of soil $\mathrm{Hg}$. Contemporary global anthropogenic $\mathrm{Hg}$ emissions are responsible for $30-40 \%$ of Arctic $\mathrm{Hg}$ deposition in winter/spring, and $25-30 \%$ in summer, of which industrial sources contribute to half and, remaining comes from artisanal and small-scale gold mining (28\%), power generation (17\%), and intentional use and product waste $(7 \%)$. Recommendations are derived to improve the assessment of concurrent impacts of Minamata Convention and climate change on Arctic mercury cycling. 